\title{
Rainfall Profiling Using Atmospheric Radiation Measurement Program Vertically Pointing 8-mm Wavelength Radars
}

\author{
SERGEY Y. Matrosov \\ Cooperative Institute for Research in Environmental Sciences, University of Colorado, and NOAA/Earth System Research \\ Laboratory, Boulder, Colorado \\ PETER T. MAY \\ Bureau of Meteorology Research Center, Melbourne, Victoria, Australia \\ Matthew D. Shupe \\ Cooperative Institute for Research in Environmental Sciences, University of Colorado, and NOAA/Earth System Research \\ Laboratory, Boulder, Colorado
}

(Manuscript received 12 December 2005, in final form 5 May 2006)

\begin{abstract}
An attenuation-based method to retrieve vertical profiles of rainfall rate from vertically pointing $\mathrm{K}_{\mathrm{a}}$-band radar measurements has been refined and adjusted for use with the U.S. Department of Energy's cloud radars deployed at multiple Atmospheric Radiation Program (ARM) test bed sites. This method takes advantage of the linear relationship between the rainfall rate and the attenuation coefficient, and can account for a priori information about the vertical profile of nonattenuated reflectivity. The retrieval method is applied to a wide variety of rainfall events observed at different ARM sites ranging from stratiform events with low-to-moderate rainfall rates $\left(\sim 5 \mathrm{~mm} \mathrm{~h}^{-1}\right)$ to heavy convective rains with rainfall rates approaching $100 \mathrm{~mm} \mathrm{~h}^{-1}$. The $\mathrm{K}_{\mathrm{a}}$-band attenuation-based retrieval results expressed in both instantaneous rainfall rates and in rainfall accumulations are compared to available surface data and measurements of a scanning C-band precipitation polarimetric radar located near the Darwin, Australia, ARM test bed site. The $\mathrm{K}_{\mathrm{a}}$-band retrievals are found to be in good agreement with the C-band radar estimates, which are based both on conventional radar reflectivity approaches and on polarimetric differential phase shift measurements. Typically, the $\mathrm{C}$-band $-\mathrm{K}_{\mathrm{a}}$-band radar estimate differences are within the expected retrieval uncertainties. The magnitude of the $\mathrm{K}_{\mathrm{a}}$-band rainfall-rate estimate error depends on the retrieval resolution, rain intensity, and uncertainties in the profiles of nonattenuated reflectivity. It is shown that reasonable retrieval accuracies $(\sim 15 \%-40 \%)$ can be achieved for a large dynamic range of observed rainfall rates (4-100 $\mathrm{mm} \mathrm{h}^{-1}$ ) and the effective vertical resolution of about $1 \mathrm{~km}$. The potential enhancements of the $\mathrm{K}_{\mathrm{a}}$-band attenuation-based method by including a priori information on vertical profiles of nonattenuated reflectivity and increasing the height range of the retrievals by using $\mathrm{K}_{\mathrm{a}}$-band polarization measurements are also discussed. The addition of the precipitation products to the suite of ARM hydrometeor retrievals can enhance the overall characterization of the vertical atmospheric column.
\end{abstract}

\section{Introduction}

One of the main objectives of the U.S. Department of Energy's (DOE) Atmospheric Measurement Program (ARM) is the comprehensive characterization of the vertical atmospheric column for the purpose of vali-

Corresponding author address: Dr. Sergey Matrosov, R/PSD2, 325 Broadway, Boulder, CO 80305.

E-mail: Sergey.Matrosov@noaa.gov dating and improving climate models (Ackerman and Stokes 2003). Water in its three phases is one of the most important components affecting the atmospheric radiation budget at different heights within the vertical column. Since its first days in the early 1990s, the ARM program has invested heavily (both financially and intellectually) in the development of remote sensing instrumentation and methods to retrieve parameters of atmospheric water vapor and clouds in both ice and liquid phases. The $\mathrm{K}_{\mathrm{a}}$-band $(34.6 \mathrm{GHz})$ millimeter 
wavelength cloud radar (MMCR; Moran et al. 1998) designed by the National Oceanic and Atmospheric Administration's Environmental Technology Laboratory (NOAA/ETL) has been one of the most successful ARM instruments for collecting vertically resolved cloud information. Long records of MMCR measurements are available from Cloud and Radiation Test bed (CART) sites located in the key areas over the globe, including Oklahoma, Alaska, Australia, and islands of the Pacific Ocean.

The ARM data archive contains detailed vertically resolved radar measurements, and some associated cloud microphysical parameter retrievals based on these measurements. Although reflectivity-based methods for retrieving drizzle parameters from groundbased $\mathrm{K}_{\mathrm{a}}$-band cloud radars exist (e.g., Frisch et al. 1995; Matrosov et al. 2004), they are not applicable to rainfall retrievals. As a result, ARM datasets lack vertically resolved quantitative information on rainfall, which is a very important component of the global water cycle that affects climate change. The absence of rainfall information in the ARM datasets presents a certain inadequacy in characterizing the vertical atmospheric column above the ARM CART sites and limits model validation efforts. Precipitation formation processes are radiatively important, and they represent one of the crucial mechanisms in the atmospheric water cycle, which are addressed by different climate and cloud models.

Vertically resolved rainfall information can be obtained from ground-based radars operating at $\mathrm{S}$ band (around $3 \mathrm{GHz}$ ) and/or from wind profilers (White et al. 2000; Williams 2002). Not all the ARM CART sites, however, are equipped with such radars. In addition their vertical resolution is typically rather coarse and there are possible effects of Bragg scattering in measurements taken at such long radar wavelengths. Furthermore, deployment of additional radars is not always feasible for a number of practical reasons. On the other hand, the MMCR measurements are routine for most of the ARM CART sites and rainfall information retrieved from these measurements can be a valuable addition to the ARM products. An important factor is also that rainfall information derived from the MMCR can have the same temporal and spatial resolutions as the cloud product information that is presented in the ARM datasets. If attenuation in rain is handled properly, the quantitative information on both clouds and precipitation can be obtained for the same atmospheric column.

An attenuation-based approach to retrieve profiles of rainfall rates from vertically pointing, 8-mm wavelength radars was recently developed (Matrosov 2005).
A simplified remote sensing method based on this approach was initially tested and applied to a case from the Cirrus Regional Study of Tropical Anvils and Cirrus Layers-Florida Area Cirrus Experiment (CRYSTAL-FACE) field project during which the NOAA-owned MMCR radar was deployed near Miami, Florida. This article shows applications and verifications of the method and describes recent enhancements and refinements that include estimating rainfall rates in the presence of noisy radar reflectivity measurements and accounting for an average vertical profile of nonattenuated reflectivity. The enhanced method is applied to several representative rainfall events from the Southern Great Plains (SGP) and the tropical western Pacific (TWP) Darwin, Australia, CART sites. The MMCR retrieval results are then compared with ground-based rainfall measurements and observations by the polarimetric scanning C-band precipitation radar, which is located near the Darwin CART site.

\section{Theoretical background}

Low-elevation scanning radar measurements have been used for quantitative precipitation estimations (QPEs) for almost five decades. Traditional radarbased estimators for rainfall use relations between radar reflectivity factor (hereafter just reflectivity) $Z_{e}$ and rainfall rate $R$ (i.e., $Z_{e}-R$ relations). Rainfall rate is proportional to the product of the drop terminal velocity $V_{t}$ and the rainwater mass, which is itself proportional to the third moment of the drop size distribution (DSD) spectra:

$$
R \sim\left\langle V_{t}(D) D^{3}\right\rangle,
$$

where $D$ is the equal-volume sphere drop diameter and the angular brackets indicate integrating over DSD, which is usually denoted as $n(D)$. Figure 1 shows the product of $V_{t}(D) D^{3}$ as a function of $D$ when values of $V_{t}$ were calculated according to Gunn and Kinzer (1949). The calculations in Fig. 1 were performed for the mean bin sizes (shown as symbols in Fig. 1) of a typical impact-type Joss-Waldvogel disdrometer (JWD) that is often used to measure rain DSD spectra (Joss and Waldvogel 1967). It can be seen from the presented calculations and a power-law approximation that

$$
R \sim\left\langle D^{3.68}\right\rangle .
$$

Reflectivity at longer radar wavelengths such as those at $\mathrm{S}$ band (frequency $v \sim 3 \mathrm{GHz}$ ) is fairly well approximated by the sixth moment of the DSD:

$$
Z_{e} \sim\left\langle D^{6}\right\rangle \text {. }
$$




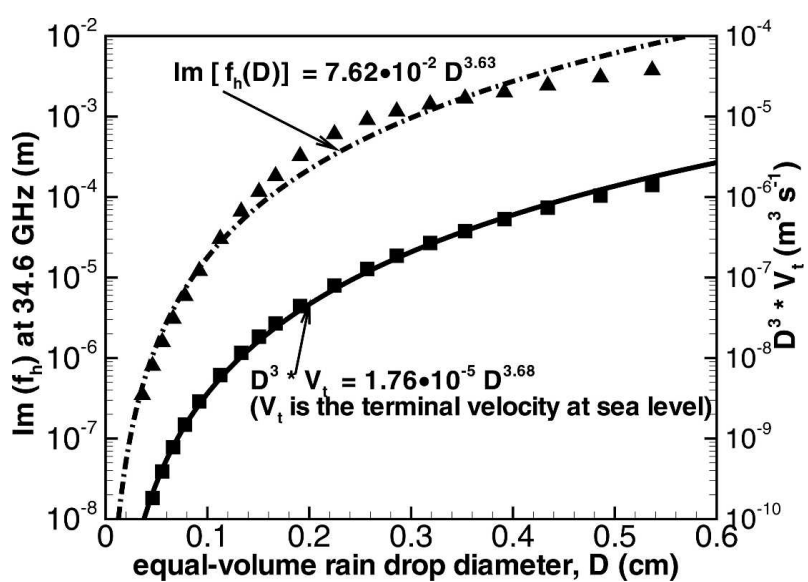

FIG. 1. Imaginary part of the forward radar amplitude at the MMCR frequency of $34.6 \mathrm{GHz}$ and the product $D^{3} V_{t}$ as functions of the equal-volume drop diameter. Symbols represent calculations at the JWD bin sizes and lines represent the power-law approximations.

Due to non-Rayleigh scattering effects, reflectivities at other frequency bands used in scanning precipitation radars (e.g., $\mathrm{C}$ band with $\nu \sim 5 \mathrm{GHz}, \mathrm{X}$ band with $\nu \sim$ $10 \mathrm{GHz}$ ) are proportional to the moments of the DSDs that are somewhat smaller than the sixth moment. Deviations from the Rayleigh-type scattering (i.e., $Z_{e} \sim$ $\left.\left\langle D^{6}\right\rangle\right)$ at these frequencies, however, are very small and can often be neglected. The $Z_{e}-R$ estimators relate 3.68th and 6th moments of DSD, and as a result they are very sensitive to the DSD variability. This variability is the major source of the uncertainty in radar QPE based on reflectivity measurements.

Polarimetric scanning radars used for precipitation studies often provide phase measurements that are then used to calculate the specific differential phase shift $K_{\mathrm{DP}}$ (Bringi and Chandrasekar 2001). Depending on the raindrop oblateness, $K_{\mathrm{DP}}$ is approximately proportional to the 4.5th-5.5th moments of the DSD. As a result, $K_{\mathrm{DP}}-R$ relations are generally less susceptible to the variability due to DSD changes than $Z_{e}-R$ relations. The $K_{\mathrm{DP}}$-based estimators often provide better measurements of rainfall rates and accumulations compared to traditional reflectivity-based techniques (Matrosov et al. 2004, 2005a).

An ideal rain-rate estimator should be based on a radar measurable parameter, which is proportional to the same moment of the DSD as the rainfall rate (i.e., the 3.68th moment). The attenuation coefficient $a$ at the $\mathrm{K}_{\mathrm{a}}$ band provides a very close approximation to such a parameter. This coefficient is given in terms of the imaginary part of the forward-scattering amplitude $f$ :

$$
a=2 \lambda \int_{0}^{D_{\max }} \operatorname{Im}[f(D)] n(D) d D
$$

where $\lambda$ is the radiation wavelength, and the maximum drop size in rain $D_{\max }$ is about $7 \mathrm{~mm}$. The radarscattering amplitudes $f$ relate to the dimensionless amplitude matrix elements used in optics, $S$, (e.g., Bohren and Huffman 1983) as $S=-2 \pi i f \lambda^{-1}$.

Figure 1 shows values of $\operatorname{Im}[f(D)]$ at the $\mathrm{K}_{\mathrm{a}}$ band as a function of the raindrop diameter. It can be seen from a power-law fit that $\operatorname{Im}[f(D)]$ can be approximated by the $3.63 \mathrm{~d}$ moment of DSD; thus,

$$
a \sim\left\langle D^{3.63}\right\rangle .
$$

Since both the rainfall rate and the attenuation coefficient at the $\mathrm{K}_{\mathrm{a}}$ band are approximately proportional to the same moment of the DSD, a practically linear $a-R$ relation results. The deviations of the empirical $a-R$ relations from linearity typically do not exceed $10 \%$, and for the MMCR frequency of $34.6 \mathrm{GHz}$ the linearized relation can be given as (Matrosov 2005):

$$
a\left(\mathrm{~dB} \mathrm{~km}^{-1}\right)=0.28 R\left(\mathrm{~mm} \mathrm{~h}^{-1}\right) .
$$

Unlike for longer radar wavelengths, the attenuation coefficient at the $\mathrm{K}_{\mathrm{a}}$ band is nearly independent of temperature and, at vertical incidence, it practically does not depend on the drop shape oblateness model (Matrosov et al. 2005b).

Being a very convenient parameter from which to infer rainfall rate, the attenuation coefficient, however, is difficult to measure. In the attenuation-based method (Matrosov 2005), $a$ is calculated as a range (height) derivative of the reflectivity measurements at vertical incidence. The heaviest assumption involved in these calculations is that at the effective vertical resolution interval, the gradual changes in the vertical profile of the apparent (i.e., measured) reflectivity due to attenuation generally prevail over those due to nonattenuated reflectivity variations. This assumption becomes progressively more substantiated as the rainfall rate and/or the resolution interval grow larger. The variability in nonattenuated reflectivity constitutes the main source of retrieval uncertainties, which were estimated in (Matrosov 2005).

It should be mentioned that the Hitschfeld and Bordan (1954) approach, which is sometimes used for retrieving the rainfall rate at modestly attenuating radar wavelengths (e.g., Testud et al. 2000), is not suitable for highly attenuated $\mathrm{K}_{\mathrm{a}}$-band radar measurements. One reason for that is that the exponent in $a-Z_{e}$ power-law relations at this band is very dependent on the details of 
the DSD (Matrosov 2005), while the constancy of this exponent is required by the Hitschfeld and Bordan approach. Besides, the $\mathrm{K}_{\mathrm{a}}$-band radar measurements are often saturated at close ranges, which prevent retrieving the profiles of nonattenuated reflectivities as part of the application of this approach.

\section{A least squares method routine for attenuation-based estimates of rainfall rates}

Retrievals of rainfall-rate $R$, using vertical measurements of attenuated reflectivity at the $\mathrm{K}_{\mathrm{a}}$ band, have many technical similarities to retrievals of $R$ based on the specific differential phase shift $K_{\mathrm{DP}}$ on propagation from low-elevation polarimetric measurements taken with longer wavelength radars such as those operating at $\mathrm{S}, \mathrm{C}$, or $\mathrm{X}$ bands. Indeed, $K_{\mathrm{DP}}$ is found as a range derivative of differential phase measurements $\Phi_{\mathrm{DP}}(r)$, while $R$ in the attenuation-based method is estimated as a range (in this case height $h$ ) derivative of attenuated reflectivity measurements $Z_{e}(h)$. In rain, both $\Phi_{\mathrm{DP}}(r)$ and $Z_{e}(h)$ are somewhat noisy measurements. A typical standard deviation (SD) value for $\Phi_{\mathrm{DP}}(r)$ data is about $1.8^{\circ}$ at $\mathrm{X}$ band (Matrosov et al. 2002), and the SD of the statistical uncertainties of $Z_{e}(h)$, even in uniform rain, can be around 0.5 dB (Marshall and Hitschfeld 1953; Matrosov and Djalalova 2001). Spurious contributions to $\Phi_{\mathrm{DP}}(r) / Z_{e}(h)$ changes with range/height are added by the differential phase shift on backscatter (for $\Phi_{\mathrm{DP}}$ ) and by the variability in vertical profiles of nonattenuated reflectivities (for $Z_{e}$ ). Since both $K_{\mathrm{DP}}$ and attenuationbased $R$ estimates are relative (not absolute) measurements, the absolute radar calibration and wet radome issues are unimportant.

Because of these similarities, a sliding "window" least squares method routine, akin to the one used with NOAA/ETL differential phase measurements (Matrosov et al. 2002; 2005a), was applied in this study to estimate $R$ from vertical profiles of MMCR reflectivity data in rain. This routine is briefly described below. After the effective resolution of retrievals, $\Delta h$ is chosen, the vertical changes of measured $Z_{e}$ are considered at an interval $h \pm \Delta h / 2$, where $h$ is a height of the resolution bin center. The $Z_{e}$ data points within this vertical interval that correspond to no-rain echoes and those that are outside the linear regime of the radar receiver (i.e., either below the receiver noise level or in the saturation regime) are rejected from further analysis. If the number of remaining data points after such thresholding is more than $50 \%$ of the original number of points in the interval, the estimate of rainfall-rate $R$ at the height $h$ is calculated as a slope of a linear fit using the least squares method:

$$
R(h)=-\frac{k(h)}{2 c} \frac{\sum_{i} Z_{e}[h(i)] h(i)-\left\{\sum_{i} Z_{e}[h(i)] \sum_{i} h(i)\right\} N^{-1}}{\sum_{i} h(i)^{2}-\left[\sum_{i} h(i)\right]^{2} N^{-1}},
$$

where the summation is performed over all remaining $N$ data points in the interval $h \pm \Delta h / 2$. If the number of remaining data points after thresholding is less than $50 \%$ of the original number of points, the rainfall estimate for such an interval is deemed unreliable. The reflectivities in (7) are in the logarithmic scale $(\mathrm{dBZ})$, the coefficient $c=0.28 \mathrm{~dB} \mathrm{~km}^{-1} \mathrm{~mm}^{-1} \mathrm{~h}^{-1}$ as in (6), and the dimensionless coefficient $k$ accounts for the raindrop fall velocity changes due to changing air density $\rho$ aloft:

$$
k(h) \approx 1.1 \rho(h)^{-0.45},
$$

where the air density is in kilograms per cubic meter.

The rainfall-rate estimates based on (7) are performed using a sliding window $\Delta h$ for all MMCR resolution gates, which are typically spaced $90 \mathrm{~m}$ apart in a rain layer. As a result, the apparent vertical resolution of retrievals is $90 \mathrm{~m}$, though the effective (actual) resolution corresponds to the interval $\Delta h$, which is typically chosen to be about $1 \mathrm{~km}$. Only data from the so-called precipitation mode of the routine MMCR measurements (Kollias et al. 2005) are used here for retrievals. This mode has the largest range of unambiguous Doppler velocity estimates $\left( \pm 15.14 \mathrm{~m} \mathrm{~s}^{-1}\right)$, which allows accurate measurements of precipitation echoes using the standard spectral processing employed with the ARM radars.

\section{Examples of retrievals of rainfall rates at the SGP ARM CART site}

The retrieval accuracies of the attenuation-based rainfall-rate profiling method strongly depend on uncertainties in the vertical profiles of nonattenuated reflectivity and the effective resolution interval $\Delta h$, and they decrease as the rainfall rate increases. The variability in the nonattenuated reflectivities is expected to be minimal in stratiform rain events, which are characterized by relatively modest rainfall rates (typically less than about $15 \mathrm{~mm} \mathrm{~h}^{-1}$ ), relatively strong radar bright bands, extensive spatial coverage, and long duration. Nonattenuated reflectivity profiles in stratiform rain are usually assumed to be constant (e.g., Andrieu and Creutin 1995). Assuming a typical 1-dB uncertainty in the nonattenuated $\mathrm{K}_{\mathrm{a}}$-band reflectivity profiles for such events, the relative errors for the discussed method can be estimated as $40 \%$ for $R=4 \mathrm{~mm} \mathrm{~h}^{-1}, 20 \%$ for $R=$ 
a) SGP, October 11, 2004

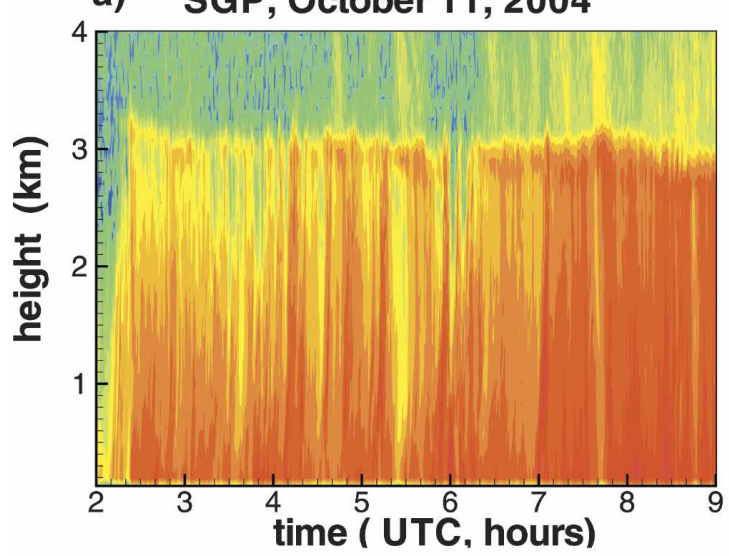

b) SGP, October 11, 2004

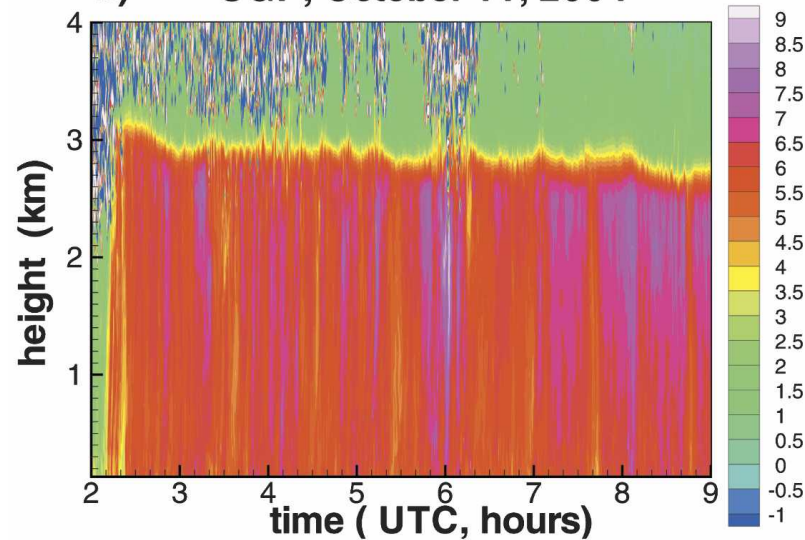

c) SGP, October 11, 2004
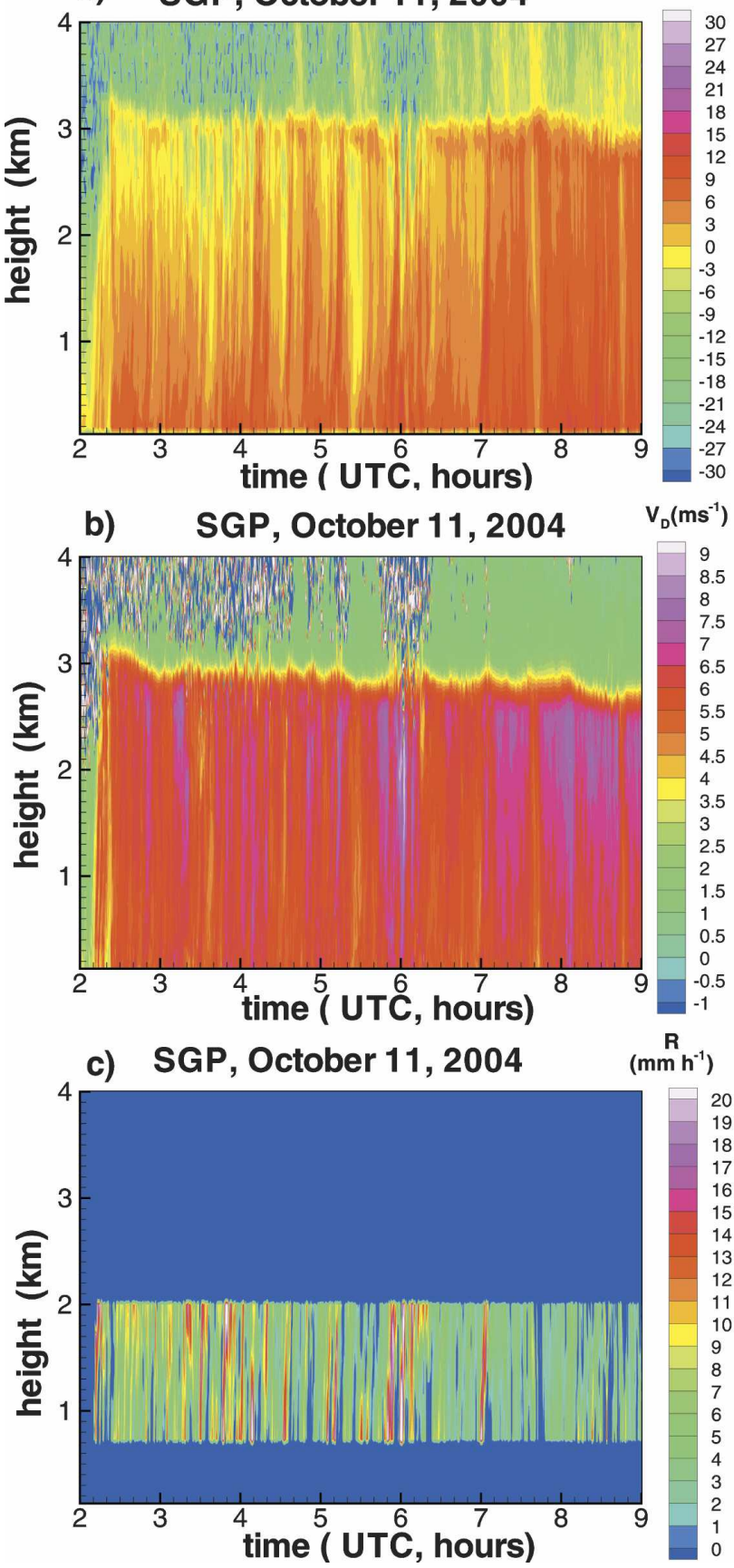

$\mathrm{V}_{\mathrm{D}}\left(\mathrm{ms}^{-1}\right)$
$\mathrm{Z}_{\mathrm{e}}(\mathrm{dBZ})$

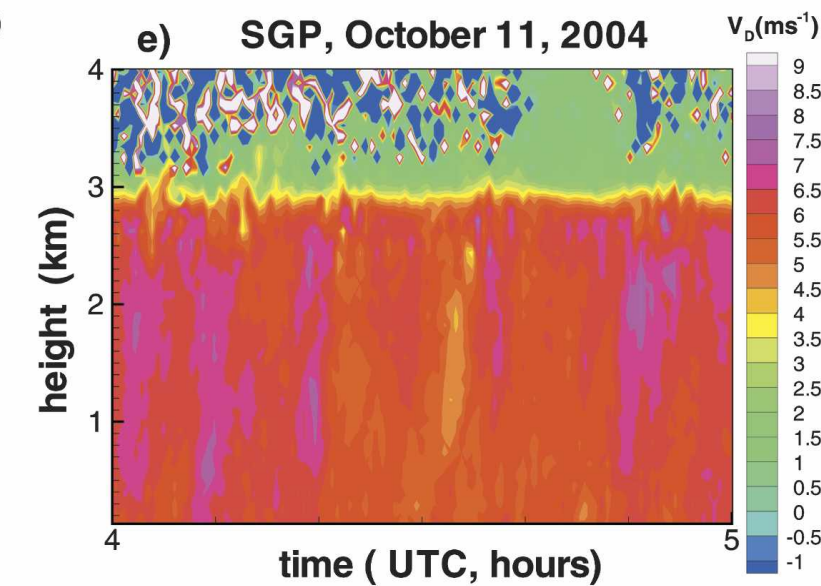

f) SGP, October 11, 2004 $\stackrel{R}{\left(\mathrm{~mm} \mathrm{~h}^{-1}\right)}$

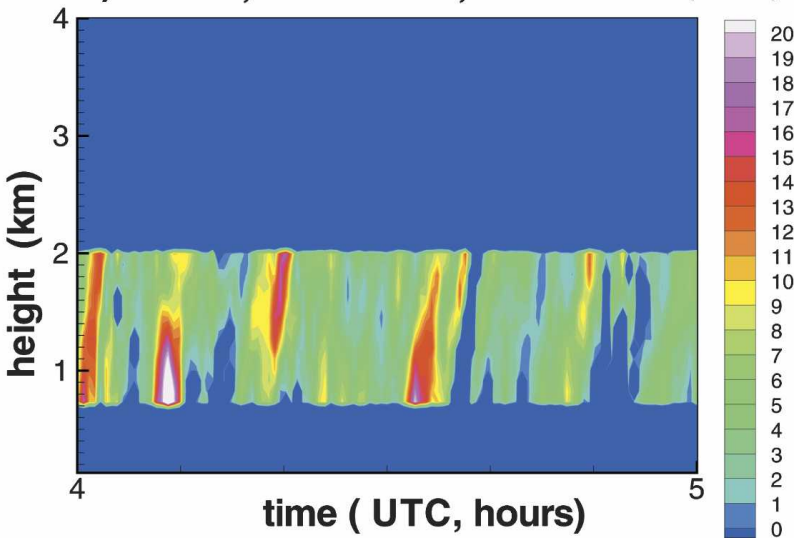

FIG. 2. Time-height cross sections of (a) MMCR-measured reflectivity, (b) mean Doppler velocity, and (c) retrieved rainfall rates for the SGP event observed on 11 Oct 2004. (d), (e), (f) One hour (0400-0500 UTC) of this event is shown in more detail.

$10 \mathrm{~mm} \mathrm{~h}^{-1}$, and $15 \%$ for $R=15 \mathrm{~mm} \mathrm{~h}^{-1}$ (Matrosov 2005).

Stratiform rainfall events are relatively common at the SGP site during fall. One such event was observed on 11 October 2004. Figures 2a,b show time-height cross sections of the MMCR-measured reflectivity and mean Doppler velocity during this event. Rainfall echoes are well defined by the high Doppler velocity measurements (Fig. 2b) and the reflectivity transition zone between the ice and liquid phase with a visible bright band (Fig. 2a). There are clear indications of signal attenuation with range in the reflectivity field. The ef- 


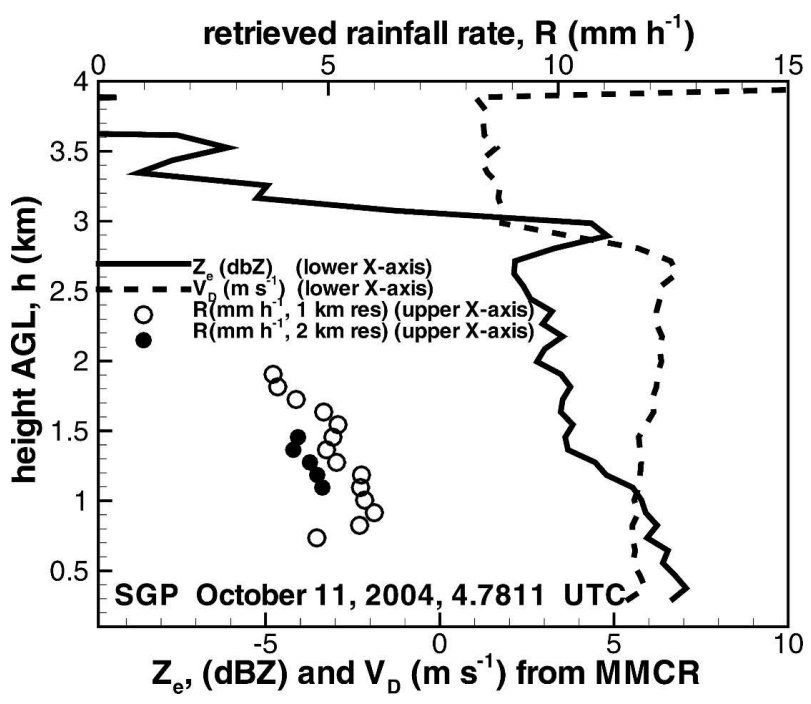

FIG. 3. Individual profiles of MMCR-measured reflectivity, mean Doppler velocity, and retrieved rainfall rates at 1- and 2-km vertical resolutions for the SGP event observed at 4.7811 UTC (decimal) 11 Oct 2004.

fects of rain attenuation on reflectivities are also seen in Fig. 3 where individual measurement profiles are shown for decimal 4.7811 UTC. Note that approximately $26 \mathrm{~dB}$ of attenuation was added before preamplifiers in this radar mode to mitigate saturation issues at closer ranges.

The reflectivity bright band in Fig. 3 is in the upper part of the transition zone from the ice to liquid phase. In this zone, the Doppler velocities change from about 1 to $2 \mathrm{~m} \mathrm{~s}^{-1}$, which is typical for snowflakes, to 5-7 $\mathrm{m} \mathrm{s}^{-1}$, which is characteristic for raindrops. According to Fig. 2b, the lower part of this transition zone during the event varied from about 3 to $2.5 \mathrm{~km}$. In a rather conservative thresholding approach to eliminate any effects of the transition zone in rainfall-rate retrievals, no data collected higher than $2.5 \mathrm{~km}$ were used for this case. For the effective resolution interval $\Delta h=1 \mathrm{~km}$, it meant that no rainfall estimates higher than about 2.0 $\mathrm{km}$ (i.e., $2.5 \mathrm{~km}-\Delta h / 2$ ) were obtained. During most of this event, MMCR reflectivity measurements were not saturated above about $0.2 \mathrm{~km}$, so the lowest available retrievals were at a height of about $0.7 \mathrm{~km}$ AGL (i.e., $0.2 \mathrm{~km}+\Delta h / 2$ ). The rainfall-rate retrievals available for this case are shown in Fig. 3 for an individual profile, and in Fig. 2c for the whole period of rain observations. Generally, values of $R$ varied between 2 and $8 \mathrm{~mm} \mathrm{~h}^{-1}$, although a few periods with $R$ at around $15 \mathrm{~mm} \mathrm{~h}^{-1}$ and even higher were observed. There was some variability in the vertical profiles of retrieved rainfall rates.

Although $\Delta h=1 \mathrm{~km}$ was used for routine retrievals in Fig. 2c, for the comparison purpose Fig. 3 shows

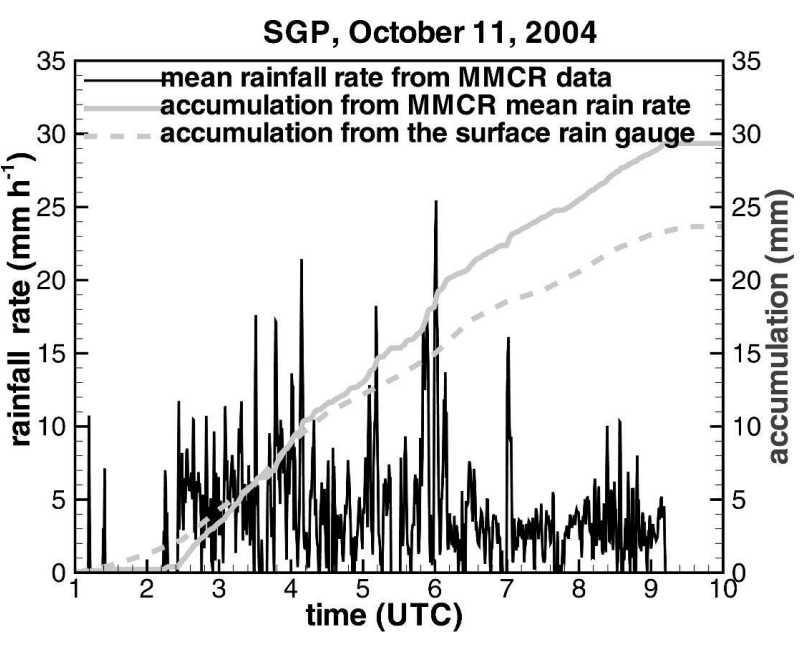

FIG. 4. Mean layer retrieved rainfall rates and accumulations from MMCR data and from the surface rain gauge for the event observed on 11 Oct 2004 at the SGP site.

individual profile retrievals for the 1- and 2-km vertical resolutions. It can be seen that the 1- and 2-km resolution retrievals agree quite well, though because of the larger interval, the $2-\mathrm{km}$ retrievals are not available higher than about $1.5 \mathrm{~km}$ or lower than about $1.1 \mathrm{~km}$. According to Matrosov (2005), expected errors for retrievals at $R \sim 4-5 \mathrm{~mm} \mathrm{~h}^{-1}$ for the $1-\mathrm{dB}$ nonattenuated reflectivity profile uncertainty are about $40 \%$ (for the $1-\mathrm{km}$ resolution) and about $25 \%$ (for the $2-\mathrm{km}$ resolution).

The average thickness of a layer where rainfall rates retrieved from MMCR data were available is about 1.3 $\mathrm{km}$. The center of this layer is located at about $1.35 \mathrm{~km}$ AGL (Fig. 2c). A time series of the mean rainfall rate $R_{m}$ in this layer is shown in Fig. 4. This figure also shows the rain accumulations calculated using $R_{m}$ and as recorded by the ground-based high-resolution (0.254 $\mathrm{mm}$ ) tipping-bucket-type rain gauge deployed at the SGP CART site near the MMCR. For this approximately 7-h rain event, the total radar-derived accumulation (using $R_{m}$ ) is about $29 \mathrm{~mm}$, which corresponds to a time-average $R_{m}$ value of about $4 \mathrm{~mm} \mathrm{~h}^{-1}$. As mentioned above, the expected retrieval accuracies of rainfall rate at such modest values of $R$ are around $40 \%$ for the resolution used $(\Delta h=1 \mathrm{~km})$. Given this and the fact that surface rain gauges are usually calibrated within $10 \%-15 \%$, the general agreement between surface gauge and radar-retrieved accumulations is good.

An approximately $20 \%$ difference between the radar-derived and surface estimates of accumulation shown in Fig. 4 is rather comparable to typical differences observed for high-resolution polarimetric scanning radars (Matrosov et al. 2005a). A part of the ob- 
served difference in this case may be attributed to the rain evaporation processes taking place near the surface. There is very good agreement between the radar data aloft and surface data between about 0320 and 0500 UTC, and also after about 0700 UTC. The radarobserved spikes in $R_{m}$ exceeding about $12 \mathrm{~mm} \mathrm{~h}^{-1}$ after 0400 UTC contributed most to the excess of the MMCR-derived rainfall accumulation compared with the surface data. However, it is difficult to expect a perfect correspondence between radar and surface datasets given the vertical separation, different sampling volumes, and uncertainties associated with both datasets. In any case, it is quite remarkable that the attenuation-based $\mathrm{K}_{\mathrm{a}}$-band radar method was able to deliver sensible vertically resolved retrievals for such modest rainfall rates.

\section{Examples of retrievals of rainfall rates at the TWP Darwin ARM CART site}

The TWP Darwin CART site has very different rain climatology than the SGP CART site. Deep convective events are common during the "wet" season, which typically lasts from November to February. It is especially instructive to test the attenuation-based $\mathrm{K}_{\mathrm{a}}$-band rainfall-rate retrieval method in this environment. The rainfall rates at the TWP site can reach $100 \mathrm{~mm} \mathrm{~h}^{-1}$ and higher. While the relative retrieval accuracy of this method improves with the increase of $R$ (Matrosov $2005)$, vertical variations of nonattenuated reflectivity in convective rains are higher than those in stratiform rains. These variations generally decrease the retrieval accuracy and offset some of the improvement due to higher values of $R$.

Compared to the SGP site, the TWP Darwin site offers more opportunities for retrieval verifications. An optical sensor at this site provides estimates of the instantaneous rainfall rates at the ground allowing for more detailed comparisons of retrievals. An important verification opportunity is also provided by the availability of data from a scanning C-band $(\lambda=5.5 \mathrm{~cm})$ polarimetric (C-Pol) radar (Keenan et al. 1998) located in the vicinity of the TWP Darwin CART site. This radar is located at a $25.5-\mathrm{km}$ distance from the MMCR and routinely performs precipitation measurements. The C-Pol radar scan sequence includes regular (once every $10 \mathrm{~min}$ or so) range-height indicator (RHI) scans at the MMCR azimuth direction $\left(\mathrm{az}=220^{\circ}\right)$, which allows for reconstruction of the C-band radar reflectivity profiles over the MMCR. Both conventional (i.e., based on $Z-R$ relations) and polarimetric (e.g., $K_{\mathrm{DP}}$ based) estimates of rainfall profiles from the C-Pol radar can be obtained over the MMCR.
Figure 5 shows the MMCR measurements and rainfall-rate retrievals (using $\Delta h=1 \mathrm{~km}$ ) for one of the convective events observed at the TWP Darwin site on 11 January 2003. The freezing level was located at an altitude of about $4.5-4.6 \mathrm{~km}$ AGL, and its manifestation can be faintly seen in Fig. 5a when reflectivities are not completely attenuated out in the warm rain layer (e.g., around 1410 UTC). Strong attenuation effects during heavy downpour periods cause the complete attenuation of MMCR signals beyond the range of just a few kilometers (e.g., at 1510 UTC), so the corresponding $R$ retrievals are limited to lower heights only. To avoid contamination by partially melted hydrometeors, the upper height of the retrievals is limited to about 3.8 $\mathrm{km}$ AGL. The lower height of the retrievals is dictated by the saturation of radar signals and the chosen effective retrieval resolution interval $(\Delta h=1 \mathrm{~km})$. For this resolution (and assuming a $2-\mathrm{dB}$ uncertainty in the nonattenuated reflectivities for convective rains), the expected uncertainties of MMCR retrievals are 35\% for $R=10 \mathrm{~mm} \mathrm{~h}^{-1}, 20 \%$ for $R=20 \mathrm{~mm} \mathrm{~h}^{-1}$, and $12 \%$ for $R=50 \mathrm{~mm} \mathrm{~h}^{-1}$ (Matrosov 2005).

Figure 6 shows layer-mean retrieved rainfall rates $R_{m}$ and accumulations from MMCR and from the surface optical rain gauge for the 11 January 2003 event. Unlike for the SGP stratiform case of 11 October 2004, the thickness of the layer where retrieval profiles are available varies significantly due to different heights at which saturation and total extinction of signals occur. The time series of the mean height of the layer where MMCR retrievals are available is also shown in Fig. 6. These mean heights vary from as low as $1 \mathrm{~km}$ AGL for the heaviest downpours, when the total signal extinction starts close to the ground to $3 \mathrm{~km}$ (or even higher) when saturation prevents retrievals at the lowest range gates. There is generally good agreement between the surface rainfall data and the MMCR-retrieved data aloft.

As an example, the vertically resolved MMCR retrievals for decimal 13.82 UTC (a time for a C-Pol RHI scan over the MMCR site) are shown in Fig. 7a. This figure also depicts a corresponding profile of C-Pol reflectivities $Z_{\mathrm{ec}}$ that were corrected for slant attenuation effects in rain (which are much smaller at the $\mathrm{C}$ band compared to the $\mathrm{K}_{\mathrm{a}}$ band) using a standard differential phase shift correction approach (e.g., Bringi and Chandrasekar 2001). The subscript "c" stands in $Z_{\mathrm{ec}}$ for the $\mathrm{C}$ band. Note that due to non-Rayleigh scattering effects, even nonattenuated $\mathrm{K}_{\mathrm{a}}$-band reflectivities are smaller than those at the $\mathrm{C}$ band. The C-Pol reflectivities and the corresponding C-Pol $K_{\mathrm{DP}}$ values (not shown) were used to estimate rainfall rates from the following estimators, which were obtained by Keenan 
a) TWP, Darwin, January 11, $2003 z_{\mathrm{e}}(\mathrm{dBz})$

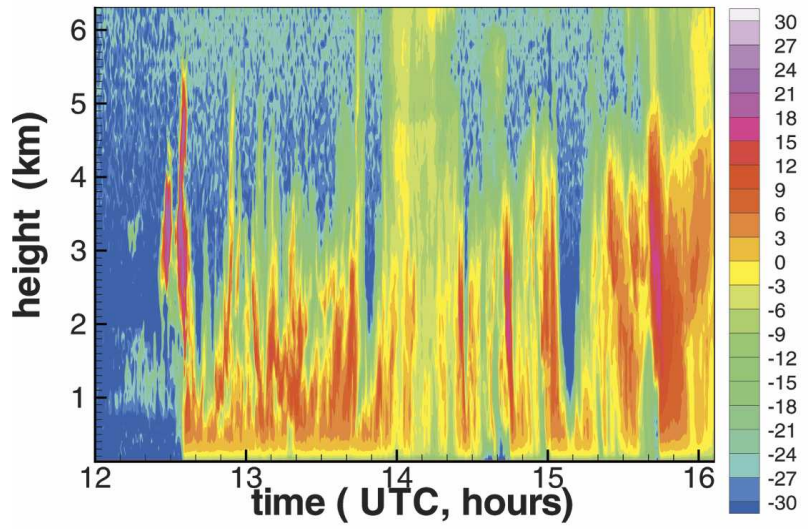

b) TWP, Darwin, January 11, $2003 \mathrm{v}_{\mathrm{D}}\left(\mathrm{ms}^{-1}\right)$
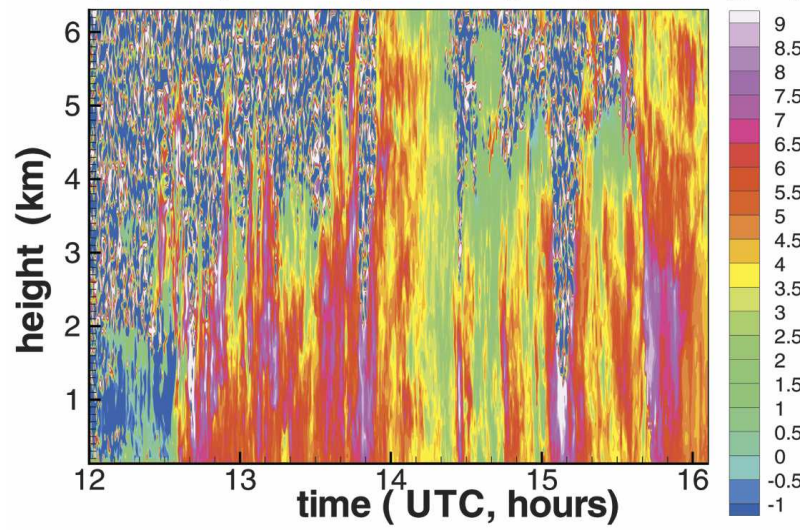

c) TWP, Darwin, January 11, $2003 \underset{\left(\mathrm{mm} \mathrm{h}^{-1}\right)}{\stackrel{R}{1}}$

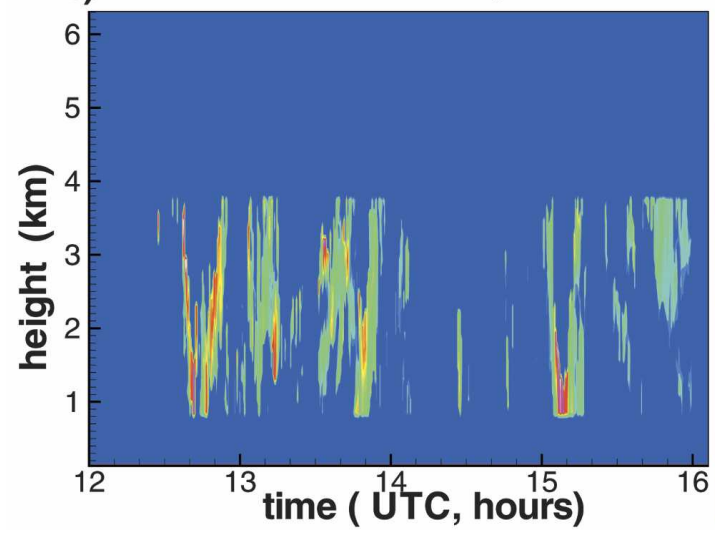

d) TWP, Darwin, January 11, $2003 \mathrm{z}_{\mathrm{e}}(\mathrm{dBz})$

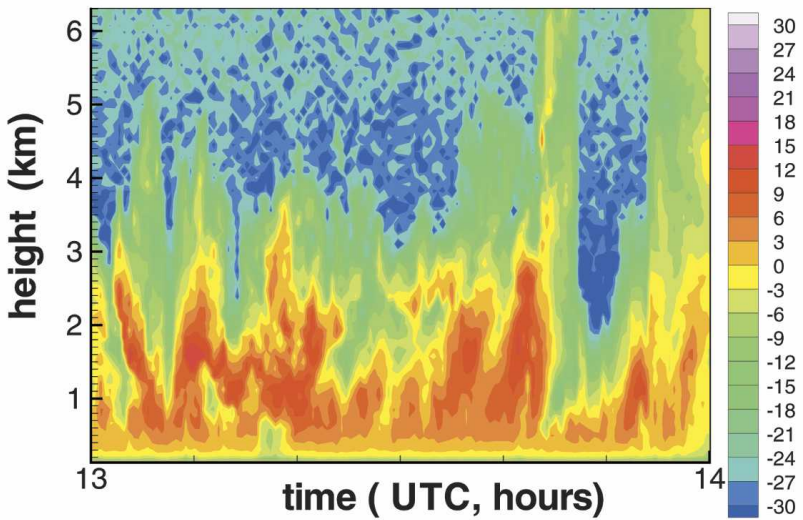

e) TWP, Darwin, January 11, $2003 \quad \mathrm{v}_{\mathrm{D}}\left(\mathrm{ms}^{-1}\right)$

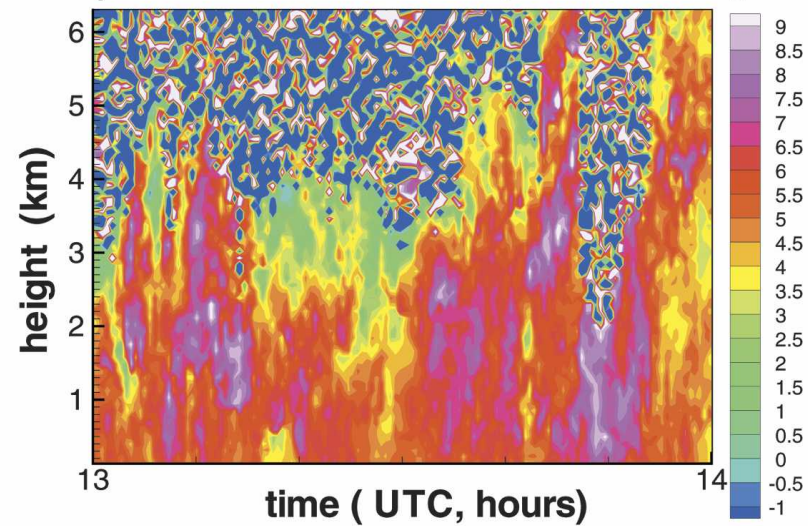

f) TWP, Darwin, January 11, $2003 \underset{\left(\mathrm{mm} \mathrm{h}^{-1}\right)}{\mathrm{R}}$

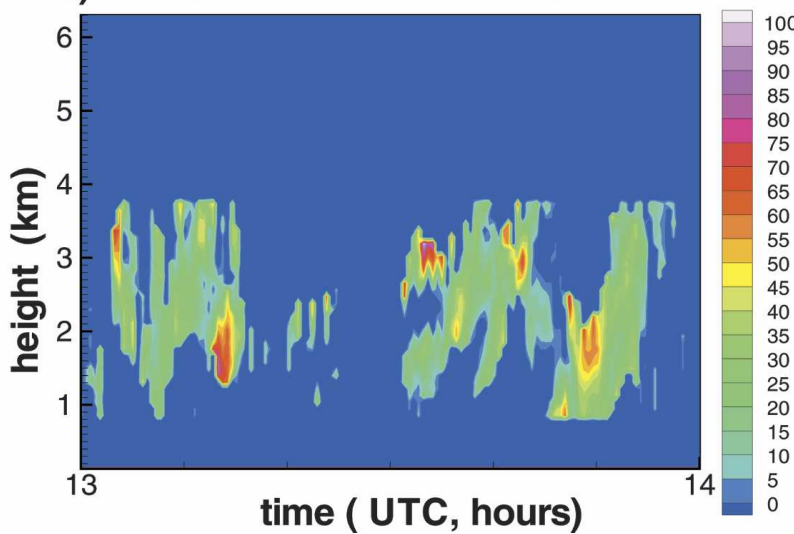

FIG. 5. Time-height cross sections of (a) MMCR-measured reflectivity, (b) mean Doppler velocity, and (c) retrieved rainfall rates for the TWP Darwin event observed on 11 Jan 2003. (d), (e), (f) One hour (1300-1400 UTC) of this event is shown in more detail.

et al. (2001) based on DSD measurements at Darwin and the Andsager et al. (1999) drop shape:

$$
\begin{aligned}
Z_{\mathrm{ec}}\left(\mathrm{mm}^{6} \mathrm{~m}^{-3}\right) & =360 R^{1.26}\left(\mathrm{~mm} \mathrm{~h}^{-1}\right), \\
R\left(\mathrm{~mm} \mathrm{~h}^{-1}\right) & =27.9 K_{\mathrm{DP}}^{0.8}\left({ }^{\circ} \mathrm{km}^{-1}\right) .
\end{aligned}
$$

The $K_{\mathrm{DP}^{-}}$and $Z_{\mathrm{ec}}$-based retrievals of rainfall rates for decimal 13.82 UTC are also shown in Fig. 7a. The $R$ estimates from both the C-Pol estimators and from the MMCR attenuation-based retrievals reach a local maximum at about $1.5-2 \mathrm{~km}$ and then exhibit a diminishing trend. MMCR values for the most part are bracketed by 


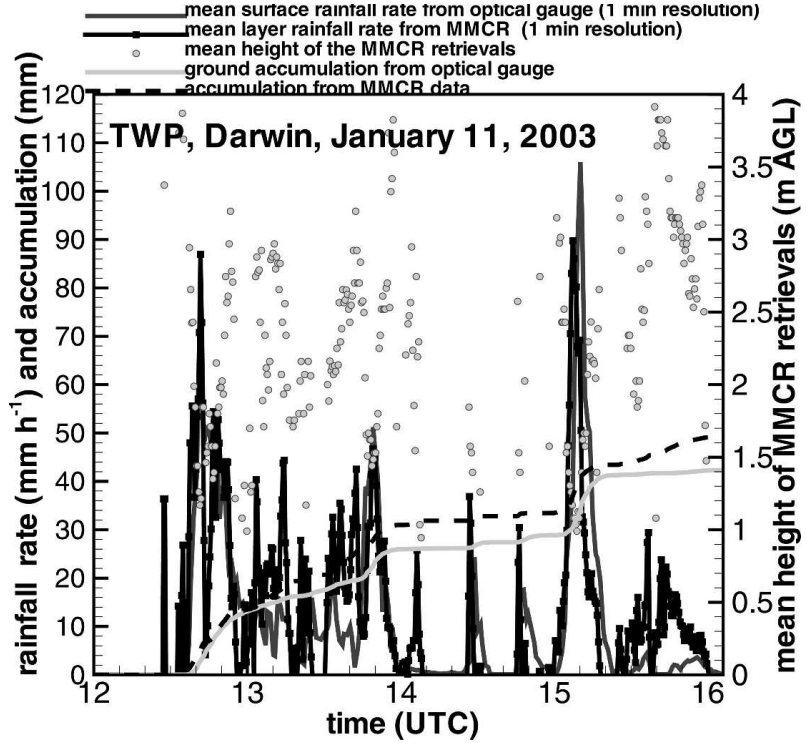

FIG. 6. Mean layer retrieved rainfall rates and accumulations from MMCR data and from the surface rain gauge for the event observed on 11 Jan 2003 at the TWP Darwin site.

the estimates from (9) and (10). Note that differences between the C-Pol $K_{\mathrm{DP}^{-}}$and $Z_{\mathrm{ec}}$-based values of $R$ at times reach a factor of 2 . This is not surprising since $Z-R$ relations are known for significant uncertainties due to DSD details, and $K_{\mathrm{DP}}-R$ relations, while generally less susceptible to DSD changes, can vary by as much as $25 \%-30 \%$ depending on the model for raindrop shapes.

Two more examples for individual profile retrievals from different rain events observed at the TWP Darwin site are depicted in Figs. 7b,c (corresponding timeheight measurement and retrieval cross sections for the entire events are not shown). For both profiles, MMCR attenuation-based $\mathrm{K}_{\mathrm{a}}$-band retrievals (where available) agree reasonably well with C-Pol estimates. While the 27 November 2002 (decimal 19.83 UTC) profile of MMCR-derived rainfall rates (Fig. 7c) shows a better agreement with $K_{\mathrm{DP}}$-based C-Pol data, the 1 January 2003 (decimal 7.32 UTC) profile from MMCR retrievals (Fig. 7b) better follows the $Z_{\mathrm{ec}}$-based C-Pol data. Overall the mean ratio of the MMCR-derived rainfall rates to the C-Pol estimates was about 1.34 (for the $K_{\mathrm{DP}}$-based C-Pol rainfall-rate values) and 0.76 (for the $Z_{\text {ec}}$-based C-Pol rainfall-rate values).

As C-Pol estimates in Figs. 7a,b, available MMCR retrievals indicate mean values of rainfall rates of about $30-50 \mathrm{~mm} \mathrm{~h}^{-1}$ while there are changes in $R$ on the order of about $10-15 \mathrm{~mm} \mathrm{~h}^{-1}$ at $1-\mathrm{km}$ intervals at certain heights. Note that the variability in nonattenuated $\mathrm{K}_{\mathrm{a}}$-band reflectivities corresponding to these changes in
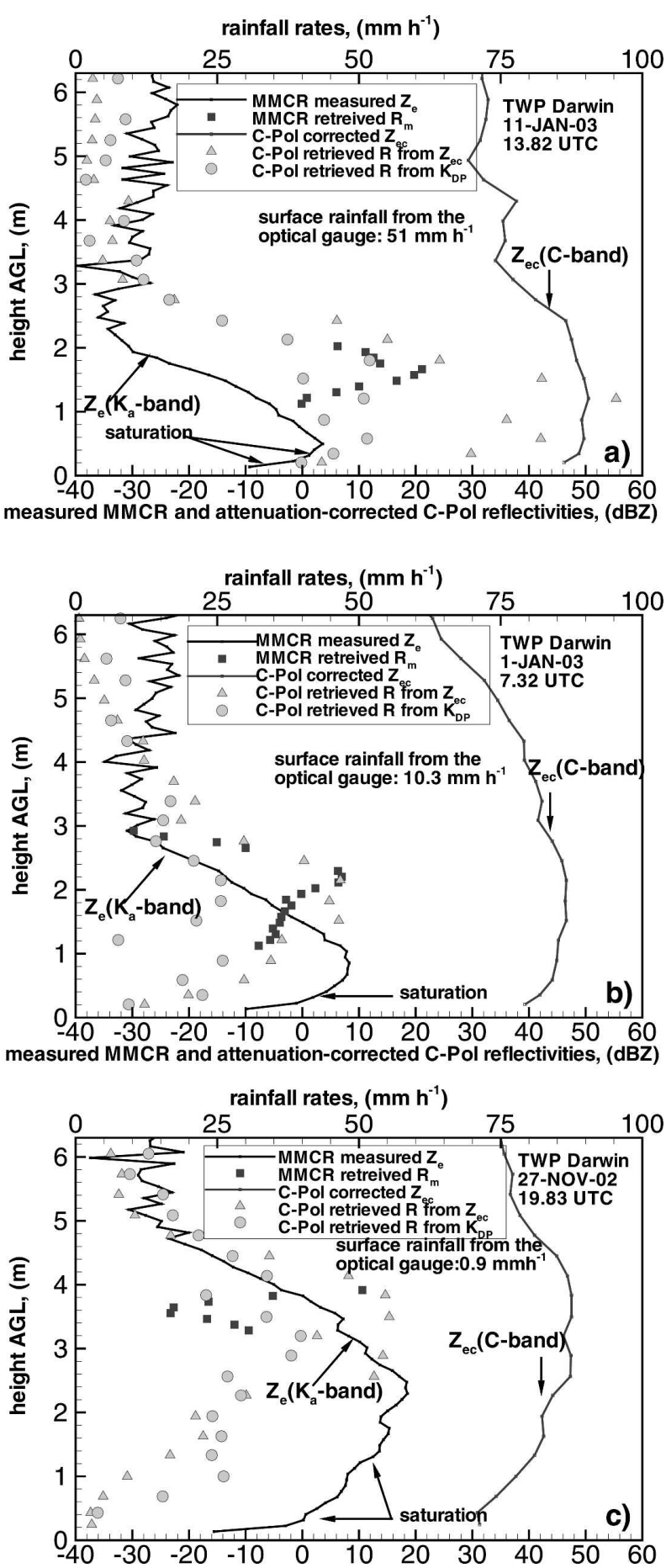

measured MMCR and attenuation-corrected C-Pol reflectivities, (dBZ)

FIG. 7. MMCR-measured and C-Pol-corrected reflectivity profiles over the TWP Darwin CART site (upper $x$ axes) and the corresponding rainfall-rate retrievals (lower $x$ axes) from MMCR (squares), from C-Pol using $Z_{\mathrm{ec}}$ (triangles), from C-Pol using $K_{\mathrm{DP}}$ (circles); (a) 13.82 UTC 11 Jan 2003, (b) 7.32 UTC 1 Jan 2003, and (c) 19.83 UTC 27 Nov 2002 (UTC times are decimal). 


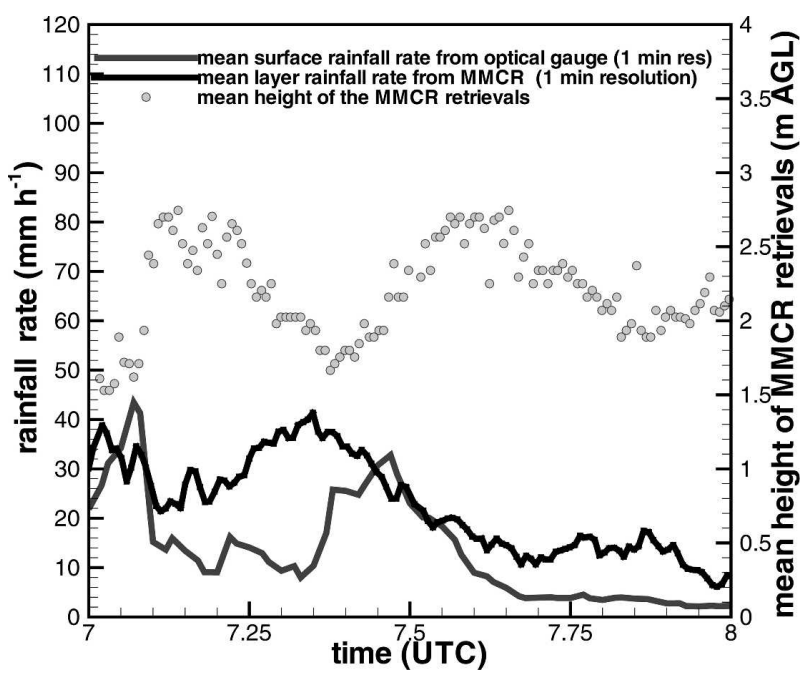

FIG. 8. Comparisons of attenuation-based retrievals of the mean layer rainfall rates aloft from MMCR and the surface values. The mean height of the layer where MMCR retrievals are available is given on the right $y$ axis.

$R$ (i.e., $30-50 \mathrm{~mm} \mathrm{~h}^{-1}$ ) typically does not exceed few decibels, while the $1-\mathrm{km}$ two-way changes of reflectivity due to attenuation exceeds $15 \mathrm{~dB}$ or so.

As mentioned above, on 11 January 2003, the ground-level rainfall rates and accumulations and those calculated using MMCR-retrieved layer-mean rainfall rates aloft $\left(R_{m}\right)$ correspond to each other rather closely (see Fig. 6). This good agreement is also seen in Fig. 7a where attenuation-based retrievals of $R$ compare well with the rainfall rate of $51 \mathrm{~mm} \mathrm{~h}^{-1}$, which was detected by the optical rain gauge at the surface. Such good correspondence, however, is not always the case. For the other two examples shown in Figs. 7b,c, rainfall rates aloft from both MMCR and C-Pol retrievals differ rather significantly from the surface values. Figure 8 shows 1-h comparisons of MMCR mean layer retrievals $R_{m}$ with surface values of rainfall rate on 1 January 2003. It can be seen that periods of good correspondence between rain aloft and at the surface can be followed by periods with notable differences. The mean layer height of MMCR retrievals for these comparisons varied between about 1.8 and $3 \mathrm{~km}$. C-Pol rainfall-rate estimates available for decimal 7.32 UTC compare well with MMCR retrievals (see Fig. 7b).

\section{Prospects for the use of vertical profiles of nonattenuated reflectivity}

In the attenuation-based retrievals presented above, the variability in vertical profiles of nonattenuated reflectivity (VPNR) at the resolution interval was regarded as the source of retrieval errors, and no attempts have been made so far to account for this variability. Neglecting vertical trends in VPNR in stratiform rain events is probably justified below the bright band. It is often done for the vertical extrapolation of scanning radar measurements when the lowest-elevation data are blocked or unavailable for some other reason (e.g., Andrieu and Creutin 1995; Smyth and Illingworth 1997). For convective rains, neglecting VPNR trends and variability is generally less justified, though as seen from $Z_{\mathrm{ec}}$ profiles in Figs. 7a,b, the aforementioned assumption of the $\pm 2 \mathrm{~dB}$ variability in nonattenuated reflectivity profiles at $\Delta h=1 \mathrm{~km}$ is generally valid when making estimates of retrieval uncertainties for these cases. Note also that the lowest-resolution element of the C-Pol radar can actually be partially blocked resulting in a smaller value of $Z_{\mathrm{ec}}$.

An idealized vertical profile of reflectivity in convective-type rains has been suggested in a number of studies (e.g., Andrieu and Creutin 1995; Smyth and Illingworth 1997). These studies indicate that there is a general decrease of reflectivity with height AGL with an average gradient of $b=2 \mathrm{~dB} \mathrm{~km}^{-1}$ or so such as

$$
Z_{e}(h)=Z_{e}(0)-b h,
$$

where nonattenuated reflectivities are understood in (11).

If such an assumption about VPNR is also made for the attenuation-based rainfall-rate retrievals, then the estimator (7) can be rewritten as

$$
R(h)=-\frac{k(h)}{2 c} \frac{\sum_{i}\left\{Z_{e}[h(i)]+b h(i)\right\} h(i)-\sum_{i}\left\{Z_{e}[h(i)]+b h(i)\right\} \sum_{i}\{h(i)\} N^{-1}}{\sum_{i} h(i)^{2}-\left[\sum_{i} h(i)\right]^{2} N^{-1}},
$$

The experience of working with TWP Darwin data, however, suggests that sometimes an opposite trend in VPNR is true when the reflectivity is decreasing toward the ground as shown by the vertical profile of $Z_{\mathrm{ec}}$ in Fig. 7 c. In such a case, the value of $b$ in (11) and (12) should be negative. Due to such conflicting indications about the sign of the VPNR gradient $b$, it was assumed in the retrievals performed in this study that $b=0$. A detailed research of VPNR in convective rainfalls at ARM CART sites using longer wavelength-scanning radars is 


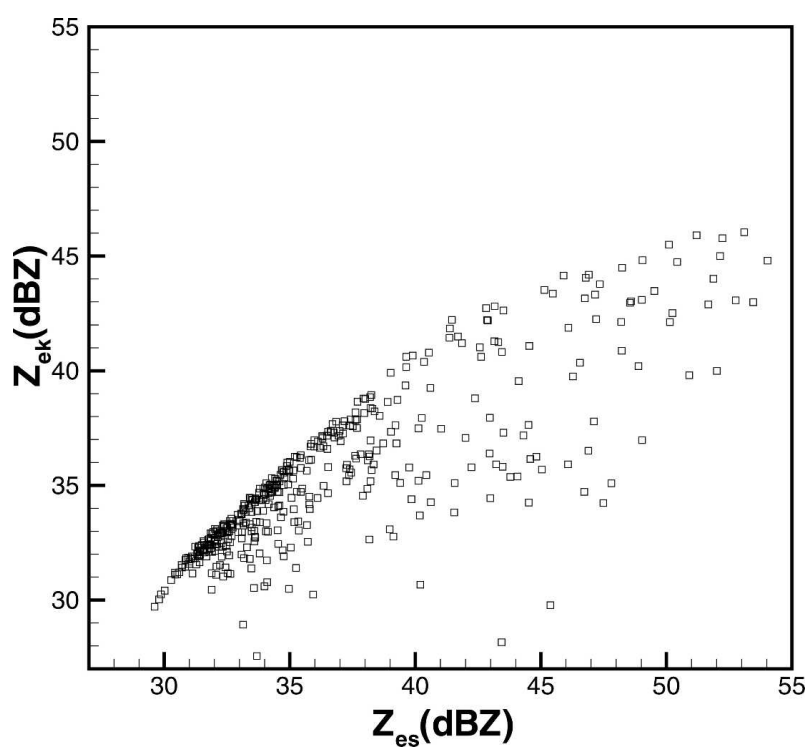

FIG. 9. Scatterplot of nonattenuated equivalent reflectivities at the $\mathrm{S}$ band, $\left[Z_{\mathrm{es}}(11 \mathrm{~cm})\right]$ and $\mathrm{K}_{\mathrm{a}}$ band $\left[Z_{\mathrm{ek}}(0.86 \mathrm{~cm})\right]$ calculated from experimental DSDs.

probably needed to further refine the $\mathrm{K}_{\mathrm{a}}$-band attenuation-based rainfall-rate retrieval method. Such research is beyond the scope of this study.

It should be mentioned, however, that though accounting for VPNR will enhance the retrieval method, VPNR variations at the $\mathrm{K}_{\mathrm{a}}$ band should be less than those for the longer wavelength radars typically used in precipitation studies (e.g., the $\mathrm{S}$ band with $\lambda \approx 11 \mathrm{~cm}$ or the $C$ band with $\lambda \approx 5.5 \mathrm{~cm}$ ). This lesser variability of $\mathrm{K}_{\mathrm{a}}$-band reflectivities, which is illustrated in Fig. 9, is explained by non-Rayleigh scattering. Calculations of equivalent reflectivities at the $\mathrm{K}_{\mathrm{a}}$ and $\mathrm{S}$ bands $\left(Z_{\mathrm{ek}}\right.$ and $Z_{\text {es }}$, respectively) in this figure were performed using the experimental JWD DSDs collected during a summer field campaign in Colorado. It can be seen that $Z_{\mathrm{ek}}$ varies less than $Z_{\text {es }}$, especially for higher reflectivity values. Most of the vertical radar reflectivity profile studies have been performed for $\mathrm{S}$ or $\mathrm{C}$ bands where non-Rayleigh effects are very often negligible, so one could expect that somewhat smaller values of the gradient parameter $b$ (in the absolute sense) would be appropriate for the $\mathrm{K}_{\mathrm{a}}$ band compared to those recommended for lower radar frequencies.

With the current assumption of $b=0$, it is helpful to identify situations in which the profiles of nonattenuated reflectivity are highly variable, in order to identify MMCR-based retrievals of rainfall rate that have higher than usual uncertainties. An example of this situation is shown in Fig. 7c where the C-Pol reflectivities, corrected for slant attenuation effects, rapidly diminish toward the ground. In this example, the MMCR retrievals are available only in the upper part of the rain where the nonattenuated $\mathrm{K}_{\mathrm{a}}$-band reflectivity variability (as judged from the $Z_{\mathrm{ec}}$ profile) is rather modest. Very often such situations can be identified using $\mathrm{K}_{\mathrm{a}}$ band radar only. They are manifested by the slanted areas of measured $\mathrm{K}_{\mathrm{a}}$-band reflectivity patterns as revealed by the time-height radar measurement cross sections in Fig. 10a. This figure shows a 0.5-h time period of data that contains the profile depicted in Fig. 7c. When the variability of nonattenuated reflectivity is relatively small (as for the 1 January 2003 case in Fig. $7 \mathrm{~b}$ ), the slanted reflectivity patterns are typically not observed as shown in Fig. 10b.

\section{Conclusions}

The attenuation-based method to retrieve profiles of rainfall rates using vertically pointing $\mathrm{K}_{\mathrm{a}}$-band radars was refined and adjusted for the use with the U.S. Department of Energy's ARM MMCR radars deployed at different CART sites. The retrieval results are tailored to the spatial and temporal resolutions of the MMCR measurements that are used for cloud remote sensing, and these results can be potentially used as precipitation value-added products in ARM data streams. Although a mean least squares sliding "window" approach allows retrieval estimates to be obtained at the 90-m radar gate intervals, the actual or effective spatial resolution $(\Delta h)$ is about $1 \mathrm{~km}$ or so. Retrieval accuracies generally diminish as the effective spatial resolution becomes coarser.

For $\Delta h=1 \mathrm{~km}$, the $\mathrm{K}_{\mathrm{a}}$-band radar rainfall retrieval method was applied to a wide variety of rainfall events ranging from cold stratiform brightband events with rainfall rates averaging about $4 \mathrm{~mm} \mathrm{~h}^{-1}$ or so to tropical convective events with rainfall rates at times reaching $100 \mathrm{~mm} \mathrm{~h}^{-1}$. Stratiform rain retrievals from the SGP site data indicated a rather modest vertical variability (generally less than a factor of 2) in estimated rainfallrate values. These retrievals expressed in terms of the accumulation time series were in good agreement with the surface tipping-bucket data. Stratiform rain results for low rainfall rates $\left(R \sim 4 \mathrm{~mm} \mathrm{~h}^{-1}\right)$ are quite encouraging given the fact that retrieval accuracies at such rainfall rates $(\sim 40 \%$ at $\Delta h=1 \mathrm{~km})$ are lower than those for higher rainfall rates (Matrosov 2005).

Retrievals for tropical convective events observed at the TWP Darwin site revealed more vertical variability in rainfall rates compared to stratiform cases. Surface rainfall was not always a good indicator for rainfall aloft. MMCR-based rainfall-rate estimates were compared with retrievals from the C-Pol polarimatric scanning precipitation radar located $25 \mathrm{~km}$ away from the 

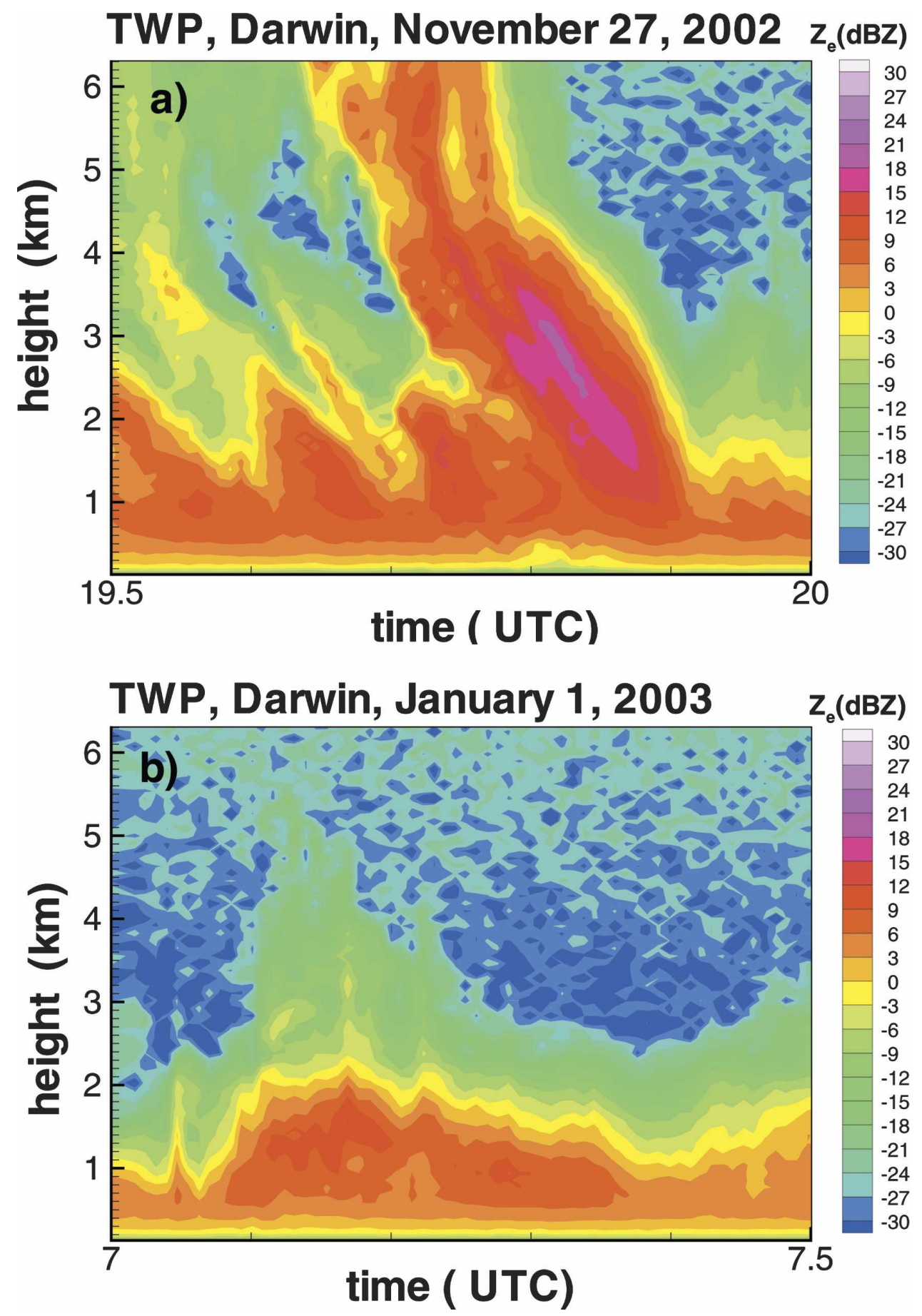

FIG. 10. Examples of (a) high and (b) low variability in nonattenuated profiles of $\mathrm{K}_{\mathrm{a}}$-band reflectivity as revealed by the measurement patterns.

ARM site. Two retrieval approaches were used with C-Pol data from the RHI scans over the MMCR site. One of these approaches uses a conventional $Z-R$ relation specially tuned to this site, and the other approach is based on differential phase $\left(K_{\mathrm{DP}}\right)$ measure- ments. For the most part, $\mathrm{K}_{\mathrm{a}}$-band attenuation-based estimates were within the range provided by C-Pol retrievals. These comparisons present an independent check of the $\mathrm{K}_{\mathrm{a}}$-band method using the precipitation radar approaches. 
It was found that the effective vertical resolution of the retrievals $\Delta h=1 \mathrm{~km}$ generally provides acceptable results, although coarser resolution can be applied in order to reduce retrieval uncertainties at the expense of losing some details in precipitation vertical structure and reducing the range where $\mathrm{K}_{\mathrm{a}}$-band radar rainfallrate retrievals are available. The current version of the method uses MMCR reflectivity data in the interval $\pm \Delta h / 2$ centered at a given radar range gate. Since the radar data, which are either in saturation or below the linear regime of radar receivers, cannot be used in retrievals, attenuation-based rainfall-rate estimates are available only in a limited vertical layer of precipitation. The thickness of this layer also depends on observed rainfall rates and the linear dynamic range of the radar receivers. For the current configuration of MMCR radars, this thickness varies from about 1 to 3 $\mathrm{km}$ for moderate rainfall rates. For high rainfall rates the thickness of such a layer can be smaller because more low-altitude range gate data are unavailable due to saturation, and intense attenuation quickly reduces radar echoes to the noise level at higher-altitude gates where signals are out of saturation.

One way to increase the useful vertical range of MMCR retrievals is to employ polarization radar measurements in the MMCR precipitation mode. In this mode echoes are recorded in the co- and crosspolarization channels. In the "weak" polarization channel (which is the copolarization channel in the circular polarization basis), radar returns are 25-30 dB lower than in the "strong" polarization channel, so the weak channel measurements can be used for rainfall-rate retrievals when the strong channel measurements are in saturation. Potentially, with a properly working MMCR polarization mode, the vertical range of retrievals can be substantially increased by adding range gates located closer to the ground. Some technological improvements in the MMCR hardware, however, are needed before this can be done.

The variability in $\mathrm{K}_{\mathrm{a}}$-band vertical profiles of nonattenuated reflectivity (VPNR) is the main contributor to the rainfall-rate retrieval uncertainties; however, due to non-Rayleigh effects, this variability is substantially smaller than that for longer-wavelength radars. VPNR variations below the bright band in stratiform rains are generally modest, and an assumption of a constant VPNR for such rains is justified. Larger VPNR variations are expected in convective rains. Though some independent studies in such rains suggest a general reflectivity increase as the AGL height diminishes, C-Pol RHI scans often reveal opposite VPNR trends. Due to such contradictory evidences, a constant VPNR was also assumed for convective retrievals, though a gener- alized estimator was developed for linear changes of VPNR with height. It was also shown that the vertical patterns in time-height cross sections of measured MMCR reflectivity can be used to distinguish between situations with high and low variability in VPNR, thus avoiding the cases with high retrieval uncertainties. Doppler velocity information potentially can also be used filter out cases with high variability in VPNR.

One more potential for reducing the adverse effect of nonattenuated reflectivity variations in future could be using more coarse temporal resolutions for retrievals. It may smooth out small-scale variability in the nonattenuated reflectivity field. That approach might be more suitable for stratiform events, which usually do not exhibit high temporal variability.

Acknowledgments. This research was supported by the Office of Science (Biological and Environmental Research), U.S. Department of Energy Grant DEFG02-05ER63954. Ken Moran of NOAA/ESRL provided valuable information about the MMCR operational modes.

\section{REFERENCES}

Ackerman, T. P., and G. Stokes, 2003: The Atmospheric Radiation Measurement Program. Phys. Today, 56, 38-45.

Andrieu, H., and J. D. Creutin, 1995: Identification of vertical profiles of radar reflectivity for hydrological applications using an inverse method. Part I: Formulation. J. Appl. Meteor., 34, 225-239.

Andsager, K., K. V. Beard, and N. F. Laird, 1999: Laboratory measurements of axis ratios for large raindrops. J. Atmos. Sci., 56, 2673-2683.

Bohren, C. F., and D. R. Huffman, 1983: Absorption and Scattering of Light by Small Particles. John Wiley and Sons, 530 pp.

Bringi, V. N., and V. Chandrasekar, 2001: Polarimetric Doppler Weather Radar. University Press, 636 pp.

Frisch, A. S., C. W. Fairall, and J. B. Snider, 1995: Measurement of stratus cloud and drizzle parameters in ASTEX with a $\mathrm{K}_{\mathrm{a}}$-band radar and a microwave radiometer. J. Atmos. Sci., 52, 2788-2799.

Gunn, R., and G. D. Kinzer, 1949: The terminal velocity of fall for water droplets in stagnant air. J. Meteor., 6, 243-248.

Hitschfeld, W., and J. Bordan, 1954: Errors inherent in the radar measurements of rainfall at attenuating wavelengths. $\mathrm{J}$. Meteor., 11, 58-67.

Joss, J., and A. Waldvogel, 1967: Ein Spectrograph fuer Niederschlagstropfen mit automatischer Auswertung. Pure Appl. Geophys., 68, 240-246.

Keenan, T. D., K. Glasson, F. Cummings, T. S. Bird, J. Keeler, and J. Lutz, 1998: The BMRC/NCAR C-band polarimetric (C-POL) radar system. J. Atmos. Oceanic Technol., 15, 871886.

_ L L. D. Carey, D. S. Zrnic, and P. T. May, 2001: Sensitivity of 5 -cm wavelength polarimetric radar variables to raindrop axial ratio and drop size distribution. J. Appl. Meteor., 40, $526-545$.

Kollias, P., B. A. Albrecht, E. E. Clothiaux, M. A. Miller, K. L. 
Johnson, and K. P. Moran, 2005: The Atmospheric Radiation Measurement program cloud profiling radars: An evaluation of signal processing and sampling strategies. J. Atmos. Oceanic Technol., 22, 930-948.

Marshall, J. S., and W. Hitschfeld, 1953: Interpretation of the fluctuating echo from randomly distributed scatterers. Part 1. Can. J. Phys., 31, 962-994.

Matrosov, S. Y., 2005: Attenuation-based estimates of rainfall rates aloft with vertically pointing $\mathrm{K}_{\mathrm{a}}$-band radars. J. Atmos. Oceanic Technol., 22, 43-54.

— , and I. V. Djalalova, 2001: Spatial variability of stratiform precipitation estimated from the X-band radar measurements. Preprints, 30th Int. Conf. on Radar Meteorology, Munich, Germany, Amer. Meteor. Soc., 612-614.

— , K. A. Clark, B. E. Martner, and A. Tokay, 2002: X-band polarimetric radar measurements of rainfall. J. Appl. Meteor., 41, 941-952.

— , T. Uttal, and D. A. Hazen, 2004: Evaluation of radar reflectivity-based estimates of water content in stratiform marine clouds. J. Appl. Meteor., 43, 405-419.

, D. E. Kingsmill, B. E. Martner, and F. M. Ralph, 2005a: The utility of X-band polarimetric radar for quantitative estimates of rainfall parameters. J. Hydrometeor., 6, 248-262.
A. J. Heymsfield, and Z. Wang, 2005b: Dual-frequency radar ratio of nonspherical atmospheric hydrometeors. Geophys. Res. Lett., 32, L13816, doi:10.1029/2005GL023210.

Moran, K. P., B. E. Martner, M. J. Post, R. A. Kropfli, D. C. Welsh, and K. B. Widener, 1998: An unattended cloudprofiling radar for use in climate research. Bull. Amer. Meteor. Soc., 79, 443-455.

Smyth, T. J., and A. J. Illingworth, 1997: Estimating rainfall rates at the ground in bright band and non-bright band events. Preprints, 28th Int. Conf. on Radar Meteorology, Austin, TX, Amer. Meteor. Soc., 125-126.

Testud, J., E. Le Bouar, E. Obligis, and M. Ali-Mehenni, 2000: The rain profiling algorithm applied to polarimetric weather radar. J. Atmos. Oceanic Technol., 17, 332-356.

White, A. B., J. R. Jordan, B. E. Martner, F. M. Ralph, and B. W. Bartram, 2000: Extending the dynamic range of an S-band radar for cloud and precipitation studies. J. Atmos. Oceanic Technol., 17, 1226-1234.

Williams, C. R., 2002: Simultaneous ambient air motion and raindrop size distributions retrieved from UHF vertical incident profiler observations. Radio Sci., 37, 1024, doi:10.1029/ 2000RS002603. 